\title{
Willingness to join and pay for Social Health Insurance among Public Servants in Arba Minch town, Gammo Zone, Southern Ethiopia
}

\section{Bahiru Mulatu}

Arba Minch College of Health Sciences

Aleme Mekuria ( $\nabla$ alemmekurishet@gmail.com )

Arbaminch College of Health Sciences

\section{Berhane Tassew}

Addis Ababa University,Ethiopia

\section{Research article}

Keywords: Social Health Insurance, Willingness to Join and Pay, Public Servants

Posted Date: May 11th, 2020

DOI: https://doi.org/10.21203/rs.3.rs-22331/v1

License: (c) (i) This work is licensed under a Creative Commons Attribution 4.0 International License.

Read Full License 


\section{Abstract}

Background Ethiopia plans to introduce social health insurance scheme for the formal sector. The scheme contribution will be collected as $3 \%$ of an employee's monthly gross salary from both employee and employer. The scheme is expected to enhance access to health care, however, there is a concern that majority of civil servants were not willing to join and pay for it. Therefore, this study aims to assess willingness to join and pay for the newly proposed social health insurance among public servants in Arba Minch town, Southern Ethiopia.

Methods Institution based, Cross-sectional study design was used among 713 randomly selected public servants in Arba Minch town. Multi-stage stratified random sampling technique was used to select participants. Data were collected by using a pre-tested, self-administered, structured questionnaire and then it was cleaned, coded, entered in to Epidata v.3.2 and exported to SPSS version 25 statistical package for analysis. Multivariate logistic regression was used to identify the predictors of willingness to join and pay for Social Health Insurance. Odds ratio less than 0.05 was used as cut-off point and $95 \% \mathrm{Cl}$ was used to report the finding. Open question contingent valuation method was also used to analyze willingness to pay for the scheme.

Result Among the total of 692 respondents, 254 (36.7\%) were willing to join the scheme. Out of those who were willing to join $171(24.7 \%)$ respondents were willing to pay less than $1 \%$ and $41(5.9 \%)$ respondents were willing to pay $2-3 \%$ of their gross monthly salary. Interest to join the scheme was found to be affected by an awareness of the scheme, household size, regularly listening for health information and participation in the social network.

Conclusion There is limited knowledge and awareness about the design of health issuance. Majority of the respondents were not willing to join and pay the proposed amount for the scheme. Provision of health information on mass media could be used as one strategy to enhance the understanding of health insurance and to change perception on social health insurance scheme.

\section{Background}

In most of developing countries the out- of- pocket payment for health care service has been accounting for over $40 \%$ of their expenditure and that limits the poor from accessing the health care and leads to complicated health problems(1).

In Ethiopia, promising improvement was seen in the domestic share of health expenditure, yet household OOP (Out Of Pocket) spending (33\%) remains a major domestic source. More than $73 \%$ of the population pay for health care from their OOP and the total per capita OOP expenditure of households for health is 231 ETB per year. As per above, the average per capita OOP is higher in urban than rural $(2,3)$.

Moreover, there could be more unidentified gaps to achieve the social health insurance in Ethiopia in general and in Arba Minch town in particular. Thus, this study has been conducted with the aim of 
assessing willingness to join and pay for the newly proposed Social health insurance among public servants in Arba Minch town, Southern Ethiopia in order to provide recommendations for policy makers and planners to take in to consideration during their plan and implementation of Social health insurance of public servants.

\section{Methods}

Institution based, cross-sectional study was conducted from $1^{\text {st }}-30^{\text {th }}$ January 2019 in Gammo Zone, Arba Minch town, Southern Ethiopia. The town has four sub cities with total population projected to be 125 , 411 of which close to $5,281(4.2 \%)$ were public servants with no health insurance coverage(7).

To calculate the sample size, the prevalence was taken from a study conducted on willingness to join and pay for SHI scheme among teachers in Wolaita Sodo town in which $45 \%$ of participants were willing to join the scheme (6).Therefore, with 0.45 proportion, $95 \%$ certainty and $5 \%$ of margin of error between population and sample considering a design effect of 2 and an anticipated non-response rate of $10 \%$, the total calculated sample size for this study was 713 public servants. Study participants who were permanent employees and Ethiopian citizens were eligible for the study.

A two-stage stratified sampling technique was used to select participants. Based on the Ethiopian Federal state institution category, we stratified the institutions in the town in to public health institutions, higher institutions and town administrative institutions. Among the public health institutions, Arba Minch General Hospital and Arba Minch Health Center were selected. Among higher institutions, Arba Minch College of Health Sciences (ACHS) and Arba Minch Teachers Training College (ATTC) were selected. And among the town administration offices of the town, Municipality, Education Office (EO), Health Offices (HO), Public Service and Human Resource Office (PSHRO), Culture, Truism and Communication Offices (CTCO) were selected. All the selected institutions were selected randomly from each of the three strata. Then after, the participating public servants were allocated to these selected institutions proportionate to the sizes of the public servants and selected using simple random sampling technique (Figure1).

Fig. 1: Schematic presentation of sampling procedure among public institutions in Arba Minch town, 2019

Six grade 12 completed students and two private workers with a Bachelor's of any field in their academic achievements were recruited to facilitate the data collection and supervision respectively. Moreover, they were clearly briefed about the purpose of the study and an intensive training on the data collection methods was given for two days. A pretested, structured, anonymous, self-administered questionnaire was used, the questionnaire was first prepared in English, translated to Amharic then back translated to English language for its consistency by two different individuals who speak both English and Amharic (the local language) fluently. 
In order to ensure the quality of the data, pretesting of the questionnaire was done in the same set-up but not from a selected institution.

Some unclear and difficult questions to understand by most of the public servants were corrected accordingly during the pre-test. The principal investigator and supervisors supervised the data collection process. The questionnaires were checked for completeness and consistency in daily basis.

Data were entered in to Epi-data V3.2, edited and then exported to SPSS version 25 statistical packages for analysis then cleaned for inconsistencies and missing values. Assumptions for logistic regression and multi-collinearity diagnostics were checked. Descriptive statistics including frequencies, percentages, mean, and standard deviations were used to describe findings. The presence of association was assessed using bivariate analysis and associations with a p-value $<0.05$ considered statistically significant. Multivariate logistic regression was used to control confounding effects and the strength of association was estimated in odds ratio and its $95 \%$ confidence interval. Variables with $p$-value $<0.2$ in the bivariate analysis were candidates for the final model.

\section{Results}

\section{Socio demographic characteristics of the respondents}

Regarding educational status, more than half, 405(58.5\%) were first degree and above holders and 360(52 $\%)$ of them were working in health facilities with mean service year of $9.5 \pm 7.2$ SD. From the total respondents, $78(11.3 \%)$ had legitimate authority in their working institution. and $33.1 \%$ don't have their own house (table 1).

\section{Table 1: Socio demographic characteristics of the respondents among public servants in Arba Minch town, 2019}




\begin{tabular}{|c|c|c|c|}
\hline Variables & Category & Frequency(n) & Percent (\%) \\
\hline \multirow[t]{5}{*}{ Age (years) } & $20-24$ & 81 & 11.7 \\
\hline & $25-29$ & 251 & 36.3 \\
\hline & $30-34$ & 146 & 21.1 \\
\hline & $35-39$ & 96 & 13.9 \\
\hline & $>39$ & 118 & 17.1 \\
\hline \multirow[t]{2}{*}{ Sex } & Male & 442 & 63.9 \\
\hline & Female & 250 & 36.1 \\
\hline \multirow[t]{2}{*}{ Marital Status } & Single & 249 & 36 \\
\hline & Married & 443 & 64 \\
\hline \multirow[t]{3}{*}{ Religion } & Orthodox & 386 & 55.8 \\
\hline & Protestant & 263 & 38 \\
\hline & Muslim & 43 & 6.2 \\
\hline \multirow[t]{3}{*}{ Family size } & $1-2$ & 276 & 39.9 \\
\hline & $2-4$ & 239 & 34.5 \\
\hline & $>4$ & 177 & 25.6 \\
\hline \multirow[t]{3}{*}{ Educational level } & Certificate \& below & 71 & 10.3 \\
\hline & Diploma & 216 & 31.2 \\
\hline & Degree \& Above & 405 & 58.5 \\
\hline \multirow[t]{3}{*}{ Working institution } & Health Facility & 360 & 52 \\
\hline & College & 276 & 39.9 \\
\hline & Town Administration & 56 & 8.1 \\
\hline \multirow[t]{4}{*}{ Service years } & $1-5$ & 265 & 38.3 \\
\hline & $5-10$ & 217 & 31.4 \\
\hline & $10-15$ & 90 & 13.0 \\
\hline & $>15$ & 120 & 17.3 \\
\hline \multirow[t]{3}{*}{ Net monthly income } & $<4000$ & 300 & 43.4 \\
\hline & $4000-6500$ & 200 & 28.9 \\
\hline & $>6500$ & 192 & 27.7 \\
\hline
\end{tabular}




\section{Health status and health expenditure}

One third of the respondents $236(34.1 \%)$ visited modern health facilities for a certain medical care within the past 12 months, of those 122(17.6\%) visited public health facilities, and 165 (23.8\%) visited modern health care facilities for less than two times in the recall period. From those who visited modern health facilities, 152 (22\%) spend less than 1000 ETB and 220(31.8\%) covered their health care expenditure from their OOP, whereas $16(2.3 \%)$ were forced to borrow money from relatives (table 2 ).

Table 2: Health and health expenditure status of the respondents among public servants in Arba Minch town, 2019

\begin{tabular}{|c|c|c|c|}
\hline Variables & Category & Frequency(n) & $\begin{array}{l}\text { Percent } \\
(\%)\end{array}$ \\
\hline \multirow[t]{2}{*}{ Got sick in the last 1-year } & Yes & 236 & 34.1 \\
\hline & No & 456 & 65.9 \\
\hline \multirow[t]{2}{*}{ Got health care } & Yes & 236 & 34.1 \\
\hline & No & 456 & 65.9 \\
\hline \multirow[t]{3}{*}{ Types of health facilities to get health care } & $\begin{array}{l}\text { Public Health } \\
\text { Facility }\end{array}$ & 122 & 17.6 \\
\hline & $\begin{array}{l}\text { Private Health } \\
\text { Facility }\end{array}$ & 73 & 10.5 \\
\hline & $\begin{array}{l}\text { both Public \& } \\
\text { Private }\end{array}$ & 40 & 5.80 \\
\hline \multirow[t]{2}{*}{ Frequency of visit to modern health care } & $<2$ times & 165 & 23.8 \\
\hline & $>2$ times & 71 & 10.3 \\
\hline \multirow{2}{*}{$\begin{array}{l}\text { ETB* }^{\star} \text { spent for modern health care in the last 1- } \\
\text { year }\end{array}$} & $<1000$ & 152 & 22.0 \\
\hline & $>1000$ & 84 & 12.1 \\
\hline \multirow[t]{2}{*}{ Covered all from OOP } & Yes & 220 & 31.8 \\
\hline & No & 16 & 2.30 \\
\hline
\end{tabular}

*Ethiopian Birr 
From the total respondents, $347(50.1 \%)$ reported that they never heard about SHI before the time of data collection. Regarding the knowledge of SHI, more than one third, 270 (39\%) knew about the benefit package of the SHI scheme (Table 3).

Table 3: Awareness about SHI scheme among formal public servants in Arba Minch town, 2019

Variables

Category
Frequency

(n)

345

347

270

68
Have you heard about SHI

Knowledge on SHI
Premium contribution

Yes

No

Benefit package

Yes

No

Yes

No
379

313

507

185
49.9

50.1

39

9.8

54.8

45.2

73.3

26.7

\section{Willingness to join and pay for SHI}

About one third, 254 (36.7\%) of respondents were willing to join and pay for the newly proposed SHI (Fig 2).

Figure 2: Willingness to join and pay for SHI scheme among public servants in Arba Minch town $(n=692)$

Among those who don't willing to join and pay for SHI, The main reason for not willing to join and pay for SHI were poor quality public health facility service, small monthly salary, lack of trust on the agency governing the contribution, Preference to use private health facilities and lack of enough information about SHI(Fig 3). 
Out of 254 respondents who were willing to join SHI, 171 (24.7\%) respondents were willing to pay less than $1 \%, 42(6.1 \%)$ were willing to pay $1-2 \%$ and $41(5.9 \%)$ respondents were willing to pay $2-3 \%$ of their gross monthly salary per month with mean $1.47 \%( \pm 0.76)$ monthly gross salary.

Fig.3: Reason for not willing to join and pay for the newly proposed SHI among public servants in Arba Minch town.

\section{Factors associated with willingness to join and pay for the newly proposed SHI}

Religion, working sector, family size, history of getting sick in the last 12 months, institution where heath care provided, knowledge about $\mathrm{SHI}$, amount of OOP health care expenditure, regularly getting for health information from mass media and social network participation had significant association with willingness to join and pay for SHI during bivariate analysis. However, awareness of SHI, family size, regularly listening for health information and participation of social network were significantly associated with willingness to join and pay for SHI during multivariate analysis. Public servants who heard about SHI were 2.4 times more likely willing to join and pay for $\mathrm{SHI}$ as compared to those who didn't heard of the scheme (AOR=2.39; 95\%; $\mathrm{Cl}, 1.59,3.75)$. Participants with $>4$ family size were $52 \%$ more likely to be willing to join and pay for $\mathrm{SHI}$ as compared to respondents with family size less than two $(\mathrm{AOR}=1.52$; $95 \% \mathrm{Cl} ; 1.32,8.82)$.

The odds of those who participate in social network were 1.6 times more likely willing to join and pay for $\mathrm{SHI}$ as compared to their counterparts(AOR=1.56;95\% $\mathrm{Cl} ; 1.04,2.36)$. Respondents who regularly follow for health information were 1.5 times more likely willing to join $\mathrm{SHI}$ as compared to those who did not follow health information (AOR=1.50; $95 \% \mathrm{Cl} ; 1.00,2.27$ ) (Table 4).

\section{Table 4: Determinants of willingness to join and pay for SHI among public servant in Arba Minch town, $2019(n=692)$}




\begin{tabular}{|c|c|c|c|c|c|c|c|}
\hline Variable & Category & WTJ & NWTJ & COR $(95 \% \mathrm{Cl})$ & PV & AOR(95\%Cl) & PV \\
\hline \multirow[t]{3}{*}{ Religion } & Orthodox & 153 & 233 & $1.52(0.76,2.99)$ & 0.67 & $0.97(0.46,2.05)$ & 0.95 \\
\hline & Protestant & 88 & 175 & $1.16(0.57,2.34)$ & 011 & $1.12(0.79,1.63)$ & 0.52 \\
\hline & Muslim & 13 & 30 & 1 & & 1 & \\
\hline \multirow[t]{3}{*}{ Family Size } & $1-2$ & 105 & 171 & 1 & & 1 & \\
\hline & $2-4$ & 92 & 147 & $1.3(0.87,1.92)$ & 0.20 & $0.72(0.48,1.09)$ & 0.190 \\
\hline & $>4$ & 57 & 120 & $1.32(0.87,1.98)$ & 0.18 & $1.52(1.33,7.82)$ & 0.011 \\
\hline \multirow[t]{3}{*}{$\begin{array}{l}\text { Working } \\
\text { Sector }\end{array}$} & $\begin{array}{l}\text { Health } \\
\text { Facility }\end{array}$ & 137 & 223 & *2(1.027,3.894) & 0.04 & $1.58(0.78,3.2)$ & 0.120 \\
\hline & College & 104 & 172 & *2.032(1.05,3.91) & 0.03 & $1.35(0.66,2.72)$ & 0.402 \\
\hline & $\begin{array}{l}\text { Town } \\
\text { Admin }\end{array}$ & 13 & 43 & 1 & & 1 & \\
\hline $\begin{array}{l}\text { Do you } \\
\text { heard of } \\
\text { SHI }\end{array}$ & Yes & 170 & 175 & $\star 3(2.2,4.2)$ & 0.001 & $\star 2.3(1.52,3.46)$ & 0.001 \\
\hline
\end{tabular}

\begin{tabular}{|c|c|c|c|c|c|c|c|}
\hline & No & 84 & 263 & 1 & & 1 & \\
\hline \multirow[t]{2}{*}{ Got Sick } & Yes & 95 & 141 & $1.25(0.911,1.74)$ & 0.16 & $1.57(0.86,2.87)$ & 0.140 \\
\hline & No & 159 & 297 & 1 & & 1 & \\
\hline \multirow{3}{*}{$\begin{array}{l}\text { Service } \\
\text { preference } \\
\text { in last one } \\
\text { year }\end{array}$} & $\begin{array}{l}\text { Private } \\
\text { facility }\end{array}$ & 57 & 65 & $0.48(0.23,1.09)$ & 0.01 & $0.47(0.20,1.06)$ & 0.070 \\
\hline & $\begin{array}{l}\text { Public } \\
\text { facility }\end{array}$ & 26 & 48 & $0.618(0.341,1.12)$ & 0.06 & $0.80(0.42,1.52)$ & 0.490 \\
\hline & Both & 12 & 28 & 1 & & 1 & \\
\hline \multirow{2}{*}{$\begin{array}{l}\text { Amount of } \\
\text { OOPP }\end{array}$} & $<1000$ & 58 & 94 & 1 & & 1 & \\
\hline & $>1001$ & 37 & 47 & $0.68(0.42,1.09)$ & 0.10 & $0.75(0.42,1.36)$ & 0.351 \\
\hline \multirow{2}{*}{$\begin{array}{l}\text { Do you get } \\
\text { health info. } \\
\text { regularly }\end{array}$} & Yes & 175 & 204 & *2.54(1.84,3.52) & 0.001 & *1.5(1.08,2.28) & 0.048 \\
\hline & No & 79 & 234 & 1 & & 1 & \\
\hline \multirow{2}{*}{$\begin{array}{l}\text { Participation } \\
\text { in Social } \\
\text { network }\end{array}$} & Yes & 205 & 302 & *1.88(1.29,2.73) & 0.001 & *1.54(1.01,2.35) & 0.040 \\
\hline & No & 49 & 136 & 1 & & 1 & \\
\hline \multicolumn{8}{|c|}{ *statistically significant at $P<.05$} \\
\hline
\end{tabular}




\section{Discussion}

The current study examines willingness to join and pay for the proposed Social Health Insurance scheme in Arba Minch town. Previous studies show that awareness and understanding of the concept of health insurance is positively associated with membership of a scheme(8). In this study, it is found that half of the respondents had never heard of the scheme. This finding similar with a study conducted at Woliata Sodo town (9). However, it is remarkably higher than studies conducted in Addis Ababa, Central Vietnam, rural population of Bangalore, India, Northwest Ethiopia, East Delhi, Andhra Pradesh and Nigeria $(6,10-$ 16). This difference could be due to the difference in sociodemographic characteristics of the previous studies and the current study area; Addis Ababa, Vietnam, India and Nigeria might have high accessibility to get the information from different medias as compared to the current study area.

With regard to willingness, only one third of the respondents were willing to join and pay for the newly proposed SHI. This finding is higher than a study conducted in St. Paul's hospital Millennium Medical College, Addis Ababa, Ethiopia, in which only $17 \%$ of the respondents were willing to pay for the scheme (14). This gap might be related to difference in selection of study subjects. In the previous study, the study subjects were only health professionals which have different monthly income packages (allowances, topup, overtime fees and other) besides their monthly salary. Therefore, they may have no significant shortage of money to pay for the scheme as compared to other employees. In our case the study subjects were selected from different public servant groups with variable range of monthly income. On the other hand, the current finding is lower than studies conducted on government employees in Mekelle city, on teachers in Wolaita Sodo, on civil servants in Northwest Ethiopia, Kampala (Uganda), and Malaysia(9, 10, 17-20). Since awareness of the scheme drives for demand, this might be attributed to low awareness of the scheme in our study area.

Majority, two third were not willing to join the scheme in the current study. The main reason for not willing to join and pay for SHI were perceptions related to poor quality public health facility service, insufficient monthly salary, lack of trust on the agency governing the contribution, preference to use private health facilities and lack of enough information about SHI.

Among the respondents who were willing to join the scheme, only one fourth were willing to pay less than or equals to $1 \%$, and few respondents were willing to pay $1-2 \%$ and $2-3 \%$ of their gross monthly salary. This finding is consistent with a study conducted in Mekelle city, Northern Ethiopia (17). Conversely, it is less than the finding seen on studies conducted in Wolaita Sodo and Vietnam $(6,15)$, in which nearly half of the study participants were willing to pay $3 \%$ and $4 \%$ respectively. The gap might be linked directly or indirectly with awareness of the scheme, participants' professional background, net income and trust on the agency overseeing the scheme.

In the current study, adequate information about SHI, family size, active engagement on different social network were significantly associated with willingness to join and pay for the SIH scheme. It was found 
that participants with large family size were more likely willing to join than families with small family size. This finding is supported by studies conducted in Debrebrehan, Ethiopia, Nigeria, India and Uganda $(8,9,20,21)$. Probably as family size increases, the probability of risk of illness will increase especially in the case of communicable illnesses. It could also be due to the increment of the health expenditure with family size in case of out-of-pocket payments that might drive for the family to impoverishment.

The likelihood of willing to join and pay for $\mathrm{SHI}$ is higher among public servants who heard about the scheme as compared to their counterparts. This finding is complemented by studies conducted on teachers' willingness to pay (WTP) in Wolaita Sodo, on civil servants' demand for SHI in Bahir Dar city and on knowledge and attitude of civil servants in Osun stata of Nigeria $(10,15,22)$. Whenever there is better information and understanding about the scheme, people will be driven to choose joining SHI.

The other determinant factor for willingness to join and pay for $\mathrm{SHI}$ is social network participation; those who participate in social networks like "Eddire" and "Ekub"(local social gatherings in Ethiopia) were more likely to have willingness to join the scheme as compared to their counterparts. This finding is supported by a study conducted in Nigeria(21).

This might be attributed to the fact that social network participation provides a good opportunity to discuss and share knowledge and experience among peers and other people in different social gatherings that fosters understanding of SHI.

\section{Conclusion}

The study revealed high level of public servants were not willing to join and pay for the newly proposed social health insurance scheme. The main reason for not willing to join and pay were poor quality health facility service, lack of trust on the agency governing the contribution, preference to private health facilities, insufficient monthly salary and lack of enough information about SHI. Awareness of SHI, family size, regularly listening for health information and participation of social network were found to be independent predictors of willingness to join and pay for the social health insurance scheme. Awareness creation. Information, Education and Communication (IEC) about SHI to the public servants is highly required before implementation of the scheme.

\section{Abbreviations}

AOR -Adjusted Odd Ratio

CBHI- Community Based Health Insurance

COR - Crude Odd Ratio

EFY - Ethiopian Fiscal Year

ETB- Ethiopian Birr 
HSTP- Health Sector Transformation Plan

NWTJ- Not Willingness To Join

OOP - Out-Of- Pocket

SHI- Social Health Insurance scheme

UHC- Universal Health Coverage

WTJ- Willingness to Join

\section{Declarations}

\section{Ethics approval and consent to participate}

Ethical clearance was obtained from Addis Ababa University Ethical Review Committee. A formal letter was submitted to the Educational office of the Gammo Zone and subsequently to public sectors of Arba Minch town where the study took place. Oral and written permissions from the sectors and the respective study subjects were obtained. The study was explained to the subjects and their consent to participate in the study was assured before completing the questionnaire.

Consent to publish: Not applicable

\section{Availability of data and materials}

The dataset supporting the conclusions of this article is included within the additional file.

\section{Competing interests}

We declare that we don't have any competing interests

\section{Funding}

This research is funded by Addis Ababa University; the fund covered costs for the design of the study, data collection, analysis, interpretation and write up the final document.

\section{Authors' Contribution}

BM: designed, conducted and analyzed the data

BT: assisted and supervised in the design of the study

AM: conducted critical review and drafted the manuscript

All authors read and approved the manuscript 


\section{Acknowledgments}

We are very thankful to Addis Ababa University school of Public Health and Medical Sciences for the financial support. Our special thanks go to the study participants for their willingness to share their idea and giving time to complete the questionnaire.

\section{Authors' Information}

${ }^{1}$ Arba Minch College of Health Sciences, Arba Minch, Ethiopia, P.O.Box $155,{ }^{2}$ Addis Ababa University, School of Public Health, Addis Ababa, Ethiopia

\section{References}

1. Kieny M-P. Research for Universal Health Coverage-the World Health Report 2013. World Health Summit yearbook. 2013;2013.

2. Ethiopia, the six health accounts $2013 / 2014$.

3. Ethiopian health accounts, household health service utilization and expenditure survey. 2015/16.

4. Health Care Financing Strategy $2017-2025$.

5. Mid-term review of Ethiopia's Health Sector Transformation Plan. December /2018;I.

6. Agago TA, Woldie M, Ololo S. Willingness to join and pay for the newly proposed social health insurance among teachers in Wolaita Sodo town, South Ethiopia. Ethiopian journal of health sciences. 2014;24(3):195-202.

7. Central Statitical Authority of Ethiopia (CSA). Population and housing Census of Ethiopia: statistical Abstract. Addis Ababa; Ethiopia: . 2007. :p. 7-8.

8. Bhat R, Jain N. Factoring affecting the demand for health insurance in a micro insurance scheme. 2006.

9. Belaynesh Abebaw* DJ, Chanie TAaT, Debre Markos University D, Markos E. Willingness to Pay for the Newly Proposed Social Health insurance Scheme and Associated Factors Among Civil Servants in Debre Markos Town, North West Ethiopia. 2015.

10. Yeshiwas S, Kiflie M, Zeleke AA, Kebede M. Civil servants' demand for social health insurance in Northwest Ethiopia. Archives of Public Health. 2018;76(1):48. 
11. Chauhan MT. A Study to assess the Awareness level about Government recognized health Insurance Schemes among the Urban Unorganized sector in East Delhi. Imperial Journal of Interdisciplinary Research. 2017.

12. Osungbade K, Olumide A, Balogun O, Famakinwa E, Jaiyeoba O. Social Health Insurance in Nigeria: Policy Implications in a Rural Community. Nigerian Medical Practitioner. 2010;57(5-6).

13. Yellaiah J. Awareness of health insurance in Andhra Pradesh. International Journal of Scientific and Research Publications. 2012;2(6):1-6.

14. Lasebew Y, Mamuye Y, Abdelmenan S. Willingness to Pay for the Newly Proposed Social Health Insurance among Health Workers at St. Paul's Hospital Millennium Medical College, Addis Ababa, Ethiopia. International Journal of Health Economics and Policy. 2017;2(4):159.

15. Hoang2 LHNaATD. Willingness to Pay for social health insurance in central Vietnam 2014.

16. Indumathi K, Hajira SI, Gopi A, Subramanian M. Awareness of health insurance in a rural population of Bangalore, India. International Journal of Medical Science and Public Health. 2016;5(10):2162-8.

17. Gidey MT, Gebretekle GB, Hogan M-E, Fenta TG. Willingness to pay for social health insurance and its determinants among public servants in Mekelle City, Northern Ethiopia: a mixed methods study. Cost Effectiveness and Resource Allocation. 2019;17(1):2.

18. Habtewold:Year: YW. Preference for health care financing options and willingness to pay for compulsory health insurance among government employees in Ethiopia,. Umeå International School of Public Health, Umeå University, Sweden 2009

19. Salameh AMM, Juni MH, Hayati K. Willingness to Pay for Social Health Insurance among Academic Staff of a Public University in Malaysia. International Journal of Public Health and Clinical Sciences. 2015;2(5):21-32.

20. Muheki CW. Willingness to pay for social health insurance: a case study of Kampala (Uganda): University of Cape Town; 1998.

21. Onemolease* HOOaEA. Determinants of Rural Household's Willingness to Participate in Community Based Health Insurance Scheme in Edo State, Nigeria 2012.

22. Al Olugbenga-Bello WA. Knowledge and attitude of civil servants in osun state, southwestern nigeria towards the national health insurance. 2010.

\section{Figures}




\section{Arba Minch Town Public Sector Employees}

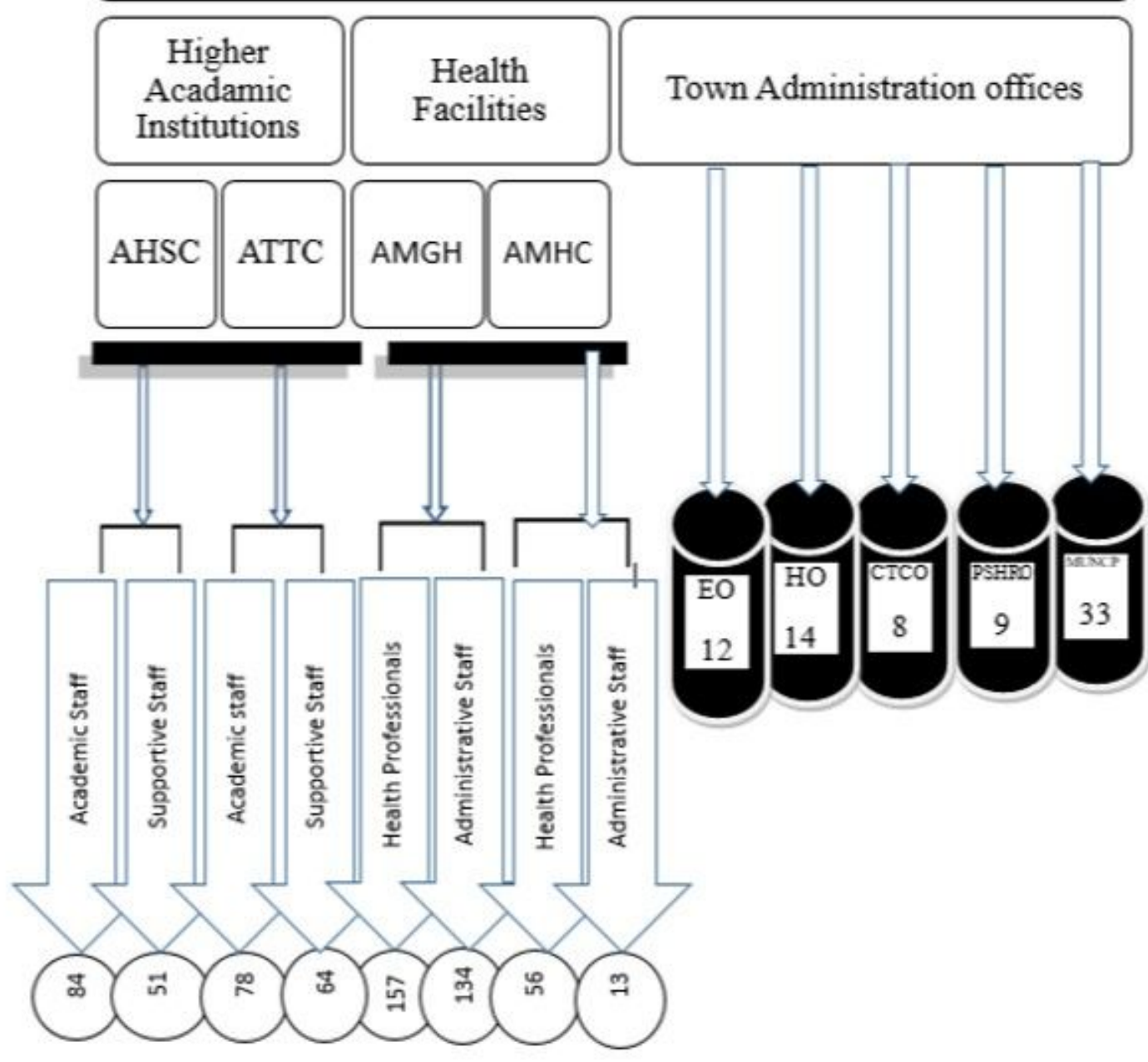

Figure 1

Schematic presentation of sampling procedure among public institutions in Arba Minch town, 2019 


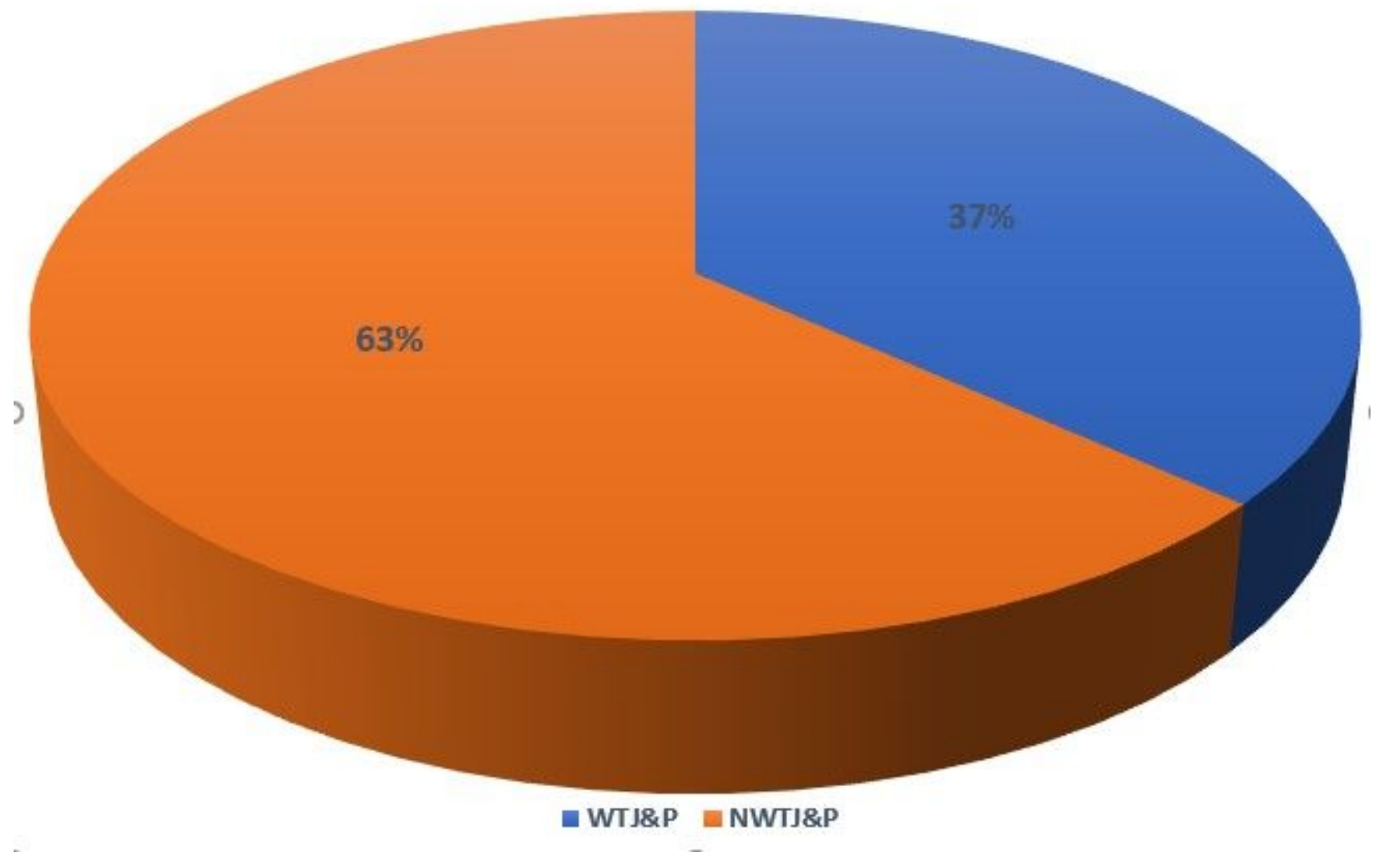

Figure 2

Willingness to join and pay for SHI scheme among public servants in Arba Minch town $(n=692)$ 


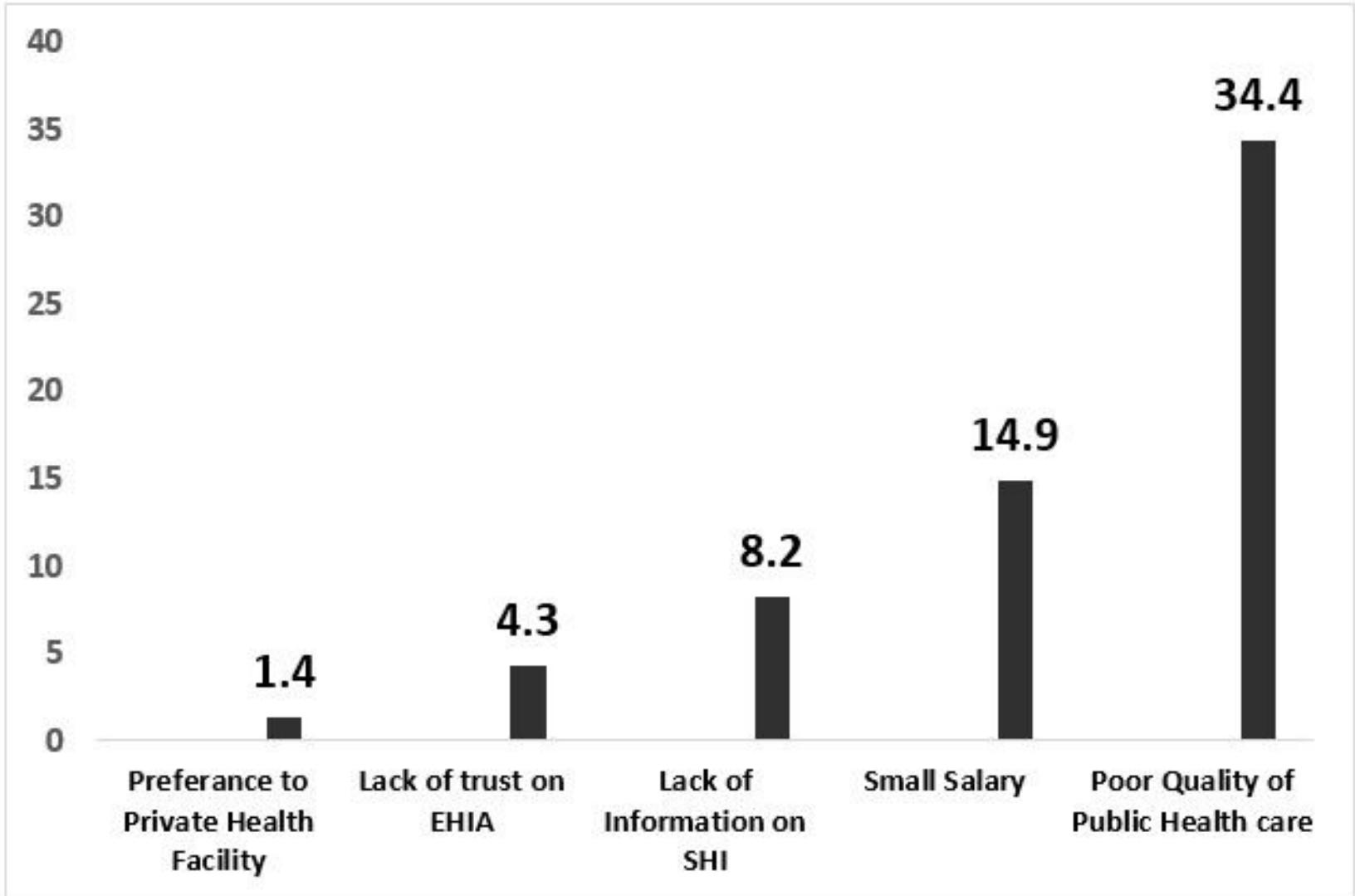

Figure 3

Reason for not willing to join and pay for the newly proposed SHI among public servants in Arba Minch town.

\section{Supplementary Files}

This is a list of supplementary files associated with this preprint. Click to download.

- STROBEchecklistcrosssectional.doc

- dataset.xls 